\title{
Chemical modification of Byrsonima crassifolia with citric acid for the competitive sorption of heavy metals from water
}

\author{
J. Monroy-Figueroa • D. I. Mendoza-Castillo • \\ A. Bonilla-Petriciolet • M. A. Pérez-Cruz
}

Received: 8 April 2014/Revised: 14 July 2014/Accepted: 7 October 2014/Published online: 21 October 2014

(C) Islamic Azad University (IAU) 2014

\begin{abstract}
This study reports the chemical modification of the Byrsonima crassifolia biomass with citric acid to improve its sorption properties for the removal of cadmium and nickel ions from aqueous solutions under competitive sorption conditions (i.e., multicomponent solutions). The best operating conditions of the chemical modification process were identified using the signal-to-noise ratio to enhance the metal uptakes and to reduce the competitive sorption effects during the simultaneous removal of these metals using the modified biomass. Results indicated that both the sorption capacity and selectivity for heavy metal removal can be improved in multicomponent metal solutions. This improvement in sorption properties of $B$. crassifolia biomass is mainly related to an increment of the acidic functional groups on the biomass surface caused by the chemical reaction between citric acid and this lignocellulosic material. The methodology reported in this study can be used to increase the sorption properties of other biomasses for the effective removal of toxic pollutants from multicomponent solutions and for the synthesis of sorbents with tailored sorption properties.
\end{abstract}

Keywords Byrsonima crassifolia $\cdot$ Wastewater treatment $\cdot$ Sorption $\cdot$ Heavy metals $\cdot$ Chemical modification

J. Monroy-Figueroa · D. I. Mendoza-Castillo .

A. Bonilla-Petriciolet $(\square)$

Instituto Tecnológico de Aguascalientes, Aguascalientes,

Mexico

e-mail: petriciolet@hotmail.com

M. A. Pérez-Cruz

Benemérita Universidad Autónoma de Puebla, Puebla, Mexico

\section{Introduction}

Over last years, the use of agroindustrial and crops wastes in the synthesis of value-added products for industrial applications has considerably increased (Ngah and Hanafiah 2008; Saka et al. 2012). In particular, literature indicates that these biomasses are attractive for water pollution control caused by organic and inorganic compounds because they are low-cost, ecofriendly, renewable and abundantly available (Sud et al. 2008; Sajab et al. 2011; Sidiras et al. 2013). These raw materials may show natural uptake properties for the removal of a great variety of toxic pollutants from water (Ngah and Hanafiah 2008). However, the sorption capacities of the raw biomasses are generally lower, sometimes in several orders of magnitude, than those reported for synthetic sorbents (Gong et al. 2008; Ngah and Hanafiah 2008). Therefore, different pretreatment methods have been used and tested to improve the sorption properties of raw biomasses, thus enhancing their exploitation and utilization in environmental applications. These procedures mainly include chemical treatments with organic compounds, oxidizing agents, bases, organic and mineral acids (Ngah and Hanafiah 2008). Specifically, the chemical reagents commonly used to enhance pollutant-binding capacities of sorbents are calcium hydroxide, sodium carbonate, sodium hydroxide, nitric acid, hydrochloric acid, sulfuric acid, tartaric acid, citric acid, formaldehyde, methanol and hydrogen peroxide. The proper conditions for the chemical treatment should be identified for effectively improving the pollutantbinding properties of the biomass. If a proper chemical modification protocol is used, the removal performance of these sorbents may increase up to one order of magnitude (Leyva-Ramos et al. 2005).

In particular, the surface chemistry modification has been recognized as a suitable approach to improving the 
sorption properties of agroindustrial by-products and wastes for the removal of heavy metals and other priority pollutants from water (Wing 1996; Vaughan et al. 2001; Reddad et al. 2002; Leyva-Ramos et al. 2005; Tan et al. 2010; Sajab et al. 2011; Altun and Pehlivan 2012; LeyvaRamos et al. 2012). Reactions between lignocellulosic biomasses and acids have been used to create alternative materials with satisfactory metal ion binding properties (Vaughan et al. 2001). Specifically, the chemical modification using citric acid offers more advantages to react with lignocellulosic materials than other modification agents because it improves the sorption properties and also increases the mechanical strength of the biomass due to the cross-linking (Altun and Pehlivan 2012). In particular, the citric acid may increase the acidic groups on the biomass surface, and, consequently, the capacity of the treated material to bind metallic ions is enhanced because these functional groups play an important role during the removal of these pollutants.

To date, different chemically modified biomasses have been reported for wastewater treatment (Ngah and Hanafiah 2008). For example, Vaughan et al. (2001) reported the modification of corncobs using citric acid and phosphoric acid for increasing its sorption capacity for the removal of cadmium, lead, zinc, copper and nickel in mono- and binary metallic solutions. Leyva-Ramos et al. (2005) studied the oxidation of corncob with both citric and nitric acids for cadmium removal from aqueous solution. In other studies, Gong et al. (2008) reported the treatment of rice straw using oxalic acid for dye removal, while orange peel biomass treated with different alkaline and acid solutions has been used for the removal of heavy metals from aqueous solution (Lu et al. 2009). Recently, Sajab et al. (2011) reported the chemical treatment of kenaf core fibers using citric acid for the removal of methylene blue from aqueous solution. Finally, Leyva-Ramos et al. (2012) performed a detailed analysis of the chemical treatment of corncob biomass using citric acid for cadmium sorption.

Herein, it is convenient to remark that several variables are involved in the chemical modification of biomass surface, which are the acid concentration, the reaction time, the temperature of the thermal treatment and the ratio of acid solution/biomass (Wing 1996). These operating conditions must be optimized to improve the removal performance of the treated material. Even though previous studies have shown the potential application of the chemical modification processes to increase the sorption properties of lignocellulosic materials, a limited attention has been paid to the use of these processes for enhancing the removal performance in multicomponent solutions (i.e., under competitive removal conditions). The study and analysis of multicomponent removal process are relevant for real-life environmental applications because wastewaters are usually constituted by different pollutants. In particular, the presence of several metallic ions in the same solution significantly decreases the removal efficacy of almost all sorbents tested in the literature (e.g., Srivastava et al. 2009; Reynel-Avila et al. 2011). This type of solutions (i.e., metal + metal) shows antagonistic removal effects (i.e., there is a competition of metal ions for the binding sites of the sorbent), and, consequently, the removal performance of biomasses under competitive conditions decreased drastically in comparison with the results obtained with mono-metallic solutions. Until now, there are no attempts to identify the best conditions of the chemical treatment for improving sorption properties of lignocellulosic biomasses using multi-metallic solutions.

Based on these facts, in this study an experimental approach based on the Taguchi experimental designs has been proposed to improve the uptake properties of Byrsonima crassifolia (BC) biomass using a chemical modification with citric acid for the removal of heavy metals under competitive sorption conditions (i.e., when more than one metal is present in the solution). BC, better known as nance or nanche, is a native fruit from southern Mexico and other countries from America (Perez-Gutierrez et al. 2010). This fruit has been traditionally used for preparing carbonated and fermented beverages including liquors. Additional commercial products obtained from its tree include edible fats and astringent bark infusion for medical treatment of diarrhea, pulmonary complaints, leucorrhea and anti-diabetic agents (Perez-Gutierrez et al. 2010). In Mexico, the consumption of this fruit has increased due to its versatility in food industry and its potential applications in medical treatments (Medina-Torres et al. 2004). Until now, the wastes of this biomass have not been used for the preparation of value-added products for environmental applications. Therefore, the metal sorption properties of the endocarp of this fruit have been studied using a chemical treatment with citric acid. In particular, binary metal solutions of nickel $\left(\mathrm{Ni}^{2+}\right)$ and cadmium $\left(\mathrm{Cd}^{2+}\right)$ ions have been selected as cases of study because these metals showed a strong antagonistic sorption. Furthermore, these heavy metals are found in the wastewaters from microelectronics and electroplating industries and can be considered relevant water pollutants (Volesky 2001; Srivastava et al. 2007, 2008). In summary, results of this study showed that it is feasible to improve the removal performance of this biomass in multi-metallic systems reducing the competitive sorption effects between metal ions in metal-metal solutions and improving the metal sorption selectivity. Finally, the proposed methodology is a general approach and can be used to increase the sorption properties of lignocellulosic biomasses via chemical treatments for the removal of toxic pollutants from multicomponent solutions. This study has been performed at Water Engineering 
and Technology Laboratory of Instituto Tecnológico de Aguascalientes (Aguascalientes, Mexico) during 2013-2014.

\section{Materials and methods}

\section{$\mathrm{BC}$ biomass description}

Fresh fruits of $\mathrm{BC}$ were collected at Colima, Mexico. Endocarp of this fruit is a hard stone and has been used as a raw material for the surface chemical treatment using citric acid, see Fig. 1a. The pulp of fruit was removed manually, the endocarp without the embryos was washed with deionized water at $50{ }^{\circ} \mathrm{C}$ until it was completely free of waste pulp, and, finally, this biomass was dried. BC endocarp samples were crushed and sieved to retain particles with a mean size of $0.5 \mathrm{~mm}$. SEM/EDX analyses of raw $\mathrm{BC}$ samples were performed to determine their superficial composition and morphology. An electron microscope DSM-942 (Zeiss) equipped with an EDX analyzer was used in this stage. On the other hand, FT-IR spectroscopy analysis was performed for identifying the functional groups of BC endocarp samples employing a Thermo Scientific Nicolet 6700 FT-IR spectrometer, while $\mathrm{X}$-ray diffraction analysis of raw biomass was performed using a Siemens D500 X-ray diffractometer. Finally, the acidic sites on both raw and modified-endocarp samples were determined by the acid-base titration method using $0.1 \mathrm{M} \mathrm{NaOH}$ and $\mathrm{HCl}$ solutions.
Fig. 1 a BC fruit, b SEM image, $\mathbf{c}$ EDX results and $\mathbf{d} \mathrm{X}$ ray pattern of raw endocarp sample, $\mathbf{e}$ acidic sites of modified-biomass samples and f FT-IR spectra of raw and modified-BC samples (a)

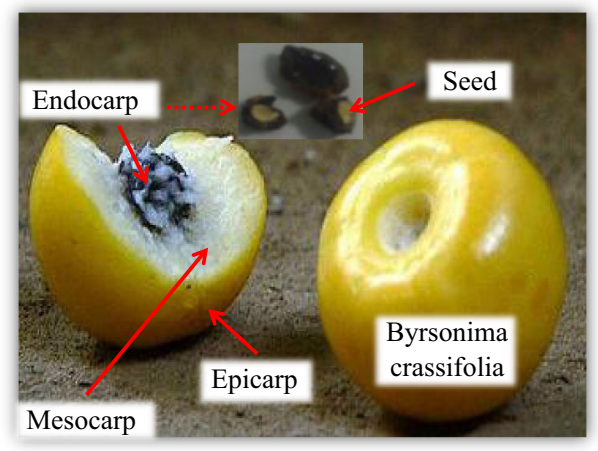

(c)

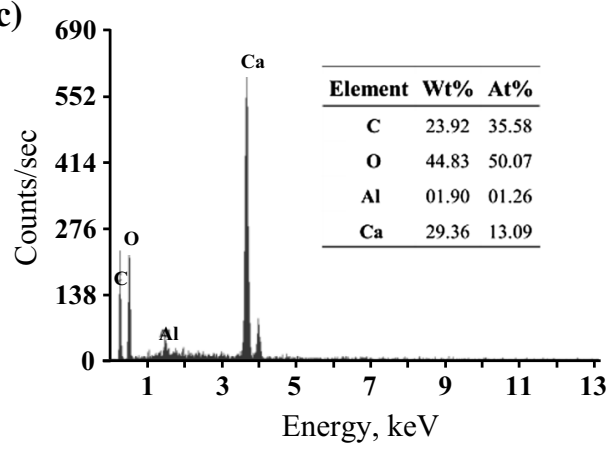

(e)

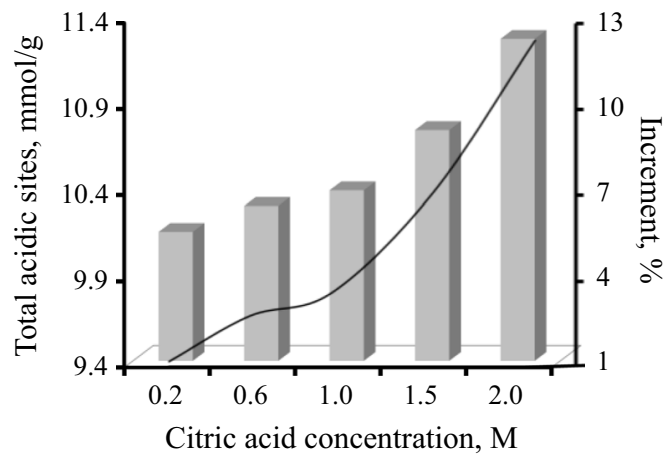

(b)

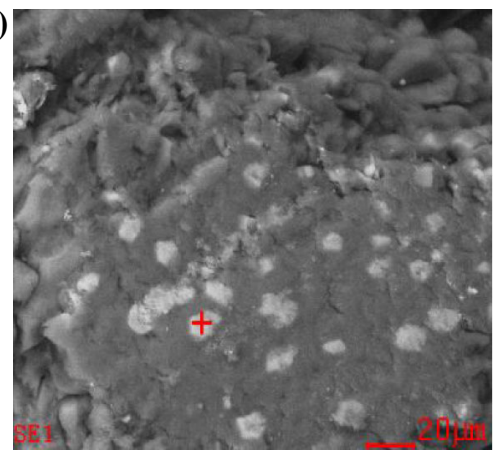

(d)

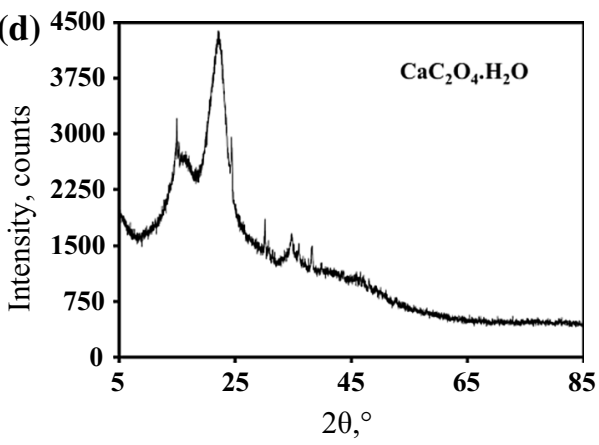

(f)

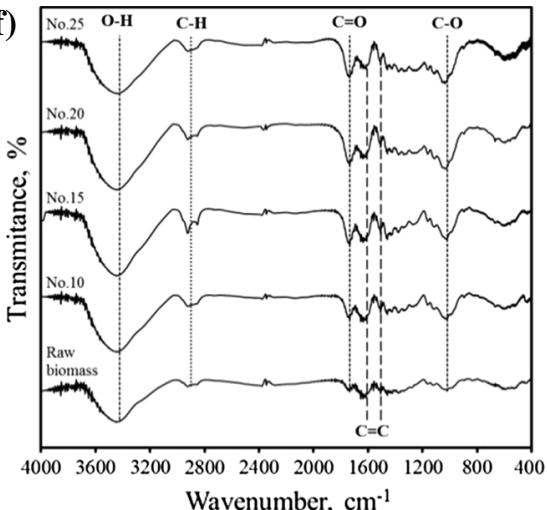


Chemical modification of $\mathrm{BC}$ biomass using citric acid

A chemical modification treatment was used to improve the sorption properties of BC endocarp samples. In particular, the methodology used in this study was performed according to the procedures reported by Marshall et al. (1999) and Leyva-Ramos et al. (2012). Figure 2 shows the main steps of this chemical treatment. Specifically, $5 \mathrm{~g}$ of BC endocarp was mixed with $25 \mathrm{~mL}$ of citric acid solution with a specified concentration. The BC biomass/acid mixture was stirred for $2 \mathrm{~h}$ at $60{ }^{\circ} \mathrm{C}$. Then, the mixture was allowed to cool and drained to separate the biomass, and the remaining liquid was discarded. This biomass was dried at $50{ }^{\circ} \mathrm{C}$ for $24 \mathrm{~h}$, and finally, the temperature of the oven was increased up to a target value, and this temperature was maintained constant during a specific heating time. Modified-biomass samples were cooled and washed with deionized water until constant $\mathrm{pH}$ and dried before they were used for the removal experiments of heavy metals.

Preliminary experiments were performed to identify those variables of the chemical treatment with the highest effect on the sorption properties of treated biomass. These variables correspond to: (1) the citric acid concentration, (2) the heating time and (3) the temperature of thermal treatment. Five experimental levels were studied for each operating variable of the chemical treatment, and the modified-BC samples were prepared according to a Taguchi experimental design (i.e., an orthogonal array $\mathrm{L}_{25}$ ) given in Table 1. With this experimental design, the $\mathrm{BC}$ endocarp was allowed to react with the citric acid at different operating conditions, and 25 experimental treatments were performed for the chemical modification process. These modified-biomass samples were prepared and used for performing the sorption experiments. The response variables of the experimental design were the sorption capacities using both mono- and bi-metallic solutions of $\mathrm{Cd}^{2+}$ and $\mathrm{Ni}^{2+}$ ions at $30{ }^{\circ} \mathrm{C}$ and $\mathrm{pH} 5$.

Metal sorption experiments using single and binary solutions of $\mathrm{Cd}^{2+}$ and $\mathrm{Ni}^{2+}$

Both single and binary metal solutions of $\mathrm{Cd}^{2+}$ and $\mathrm{Ni}^{2+}$ were used for sorption experiments. These solutions were prepared using deionized water and nitrate salts of $\mathrm{Cd}^{2+}$ (J.T. Baker) and $\mathrm{Ni}^{2+}$ (Sigma Aldrich). In single metal experiments, solution concentrations ranged from 25 to $100 \mathrm{mg} / \mathrm{L}$. On the other hand, $\mathrm{Cd}^{2+}-\mathrm{Ni}^{2+}$ binary solutions were prepared with different initial contents of both metals, i.e., 25-25, 25-50, ..., 100-100 mg/L. In fact, 16 binary metal solutions were used in sorption experiments employing raw and modified-BC samples. Sorption experiments were performed using a biomass/solution ratio of $15 \mathrm{~g} / \mathrm{L}$ at $30{ }^{\circ} \mathrm{C}$ and $\mathrm{pH}$ 5. Equilibrium time for sorption

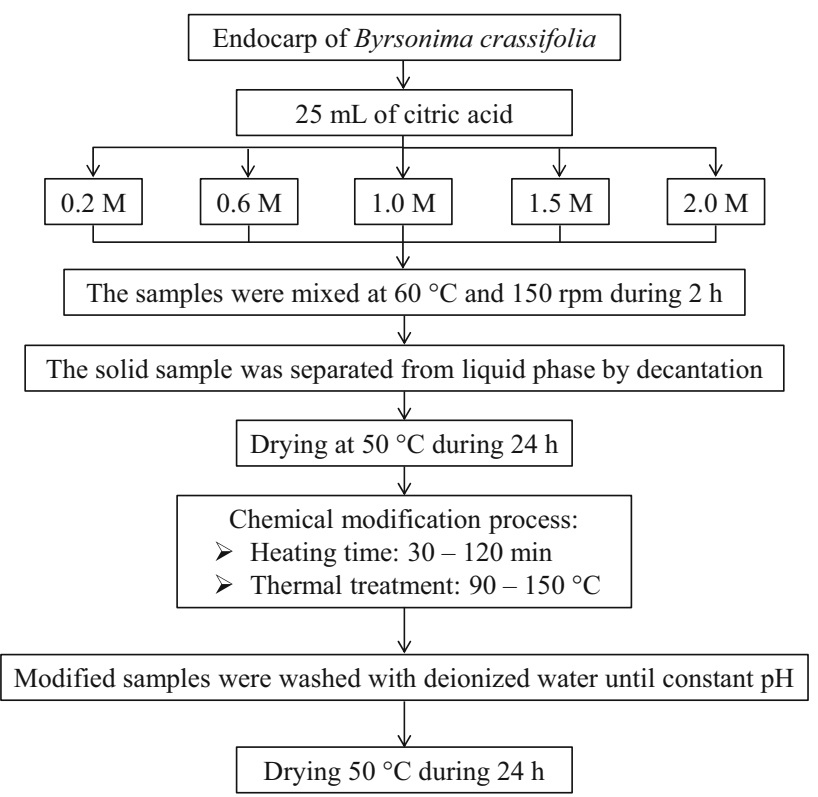

Fig. 2 Flowchart of the chemical treatment of $B$. crassifolia using citric acid

experiments using both single and binary metal solutions was $24 \mathrm{~h}$. Metal concentrations were quantified using the atomic absorption spectroscopy technique. In particular, a PerkinElmer AAnalyst 100 atomic absorption spectrometer was employed. All experiments were conducted in duplicate, and the mean value was used for data analysis of the experimental design. Metal uptakes were calculated from the removal experiments using a mass balance.

$q_{e, i}=\frac{\left(\left[M^{2+}\right]_{0}-\left[M^{2+}\right]_{e}\right) V}{m}$

where $q_{e, i}$ is the sorption capacity of BC sample for metal ion $i,\left[M^{2+}\right]_{0}$ is the initial concentration of metal ion $i$ in the solution, $\left[M^{2+}\right]_{e}$ is the equilibrium concentration of metal $i$ in the solution after sorption process, $V$ and $m$ are the volume of metal solution (single or binary) and the mass amount of BC sample used in sorption experiments, respectively.

Data analysis of the experimental design for improving the sorption properties of modified-BC samples

The analysis of metal removal data was performed using a variance analysis of the $L_{25}$ experimental design with the signal-to-noise ratio $(\mathrm{S} / \mathrm{N})$. This $\mathrm{S} / \mathrm{N}$ ratio was used to identify the best operating conditions of the chemical treatment for improving the removal performance of modified-biomass samples. The $\mathrm{S} / \mathrm{N}$ ratio is defined as.

$S / N=-10 \log \left(\frac{1}{n_{\text {rep }}} \sum_{i=1}^{n_{\text {rep }}}\left[\frac{1}{x_{i}^{2}}\right]\right)$ 
Table 1 Metal sorption capacities and multicomponent removal performance of modified-biomass samples obtained from the chemical treatment of $\mathrm{BC}$ using citric acid and $\mathrm{L}_{25}$ experimental design

\begin{tabular}{|c|c|c|c|c|c|c|c|c|c|c|c|c|c|}
\hline \multirow[t]{2}{*}{$\begin{array}{l}\text { Sample } \\
\text { No. }\end{array}$} & \multicolumn{3}{|c|}{ Conditions of the chemical modification process } & \multicolumn{2}{|c|}{$\begin{array}{l}q_{e}(\mathrm{mg} / \mathrm{g}) \\
\text { for }\end{array}$} & \multicolumn{4}{|c|}{$\begin{array}{l}R_{q T} \text { for } \mathrm{Cd}^{2+} \text { with co-ion } \\
\text { concentration }(\mathrm{mg} / \mathrm{L}) \text { of }\end{array}$} & \multicolumn{4}{|c|}{$\begin{array}{l}R_{q T} \text { for } \mathrm{Ni}^{2+} \text { with co-ion } \\
\text { concentration }(\mathrm{mg} / \mathrm{L}) \text { of }\end{array}$} \\
\hline & $\begin{array}{l}\text { Citric acid concentration } \\
\text { (M) }\end{array}$ & $\begin{array}{l}\text { Heating time } \\
(\min )\end{array}$ & $\begin{array}{l}\text { Temperature, } \\
{ }^{\circ} \mathrm{C}\end{array}$ & $\mathrm{Ni}^{2+}$ & $\mathrm{Cd}^{2+}$ & 25 & 50 & 75 & 100 & 25 & 50 & 75 & 100 \\
\hline 1 & 0.2 & 30 & 90 & 1.38 & 1.75 & 2.90 & 2.57 & 2.26 & 1.99 & 3.54 & 3.26 & 2.55 & 2.14 \\
\hline 2 & 0.2 & 60 & 110 & 0.97 & 1.95 & 2.98 & 2.48 & 2.07 & 1.73 & 2.98 & 2.34 & 2.10 & 1.81 \\
\hline 3 & 0.2 & 80 & 120 & 1.32 & 1.85 & 3.03 & 2.41 & 2.09 & 1.70 & 1.68 & 1.26 & 0.91 & 0.57 \\
\hline 4 & 0.2 & 100 & 130 & 0.97 & 1.84 & 2.97 & 2.51 & 2.22 & 2.27 & 2.04 & 1.68 & 1.38 & 0.98 \\
\hline 5 & 0.2 & 120 & 150 & 0.97 & 1.99 & 2.68 & 2.25 & 1.97 & 1.60 & 3.09 & 2.67 & 2.35 & 2.10 \\
\hline 6 & 0.6 & 30 & 110 & 1.13 & 1.93 & 2.68 & 2.20 & 1.81 & 1.54 & 3.40 & 2.87 & 2.44 & 1.58 \\
\hline 7 & 0.6 & 60 & 120 & 1.21 & 2.33 & 2.76 & 2.33 & 2.16 & 1.94 & 3.51 & 2.86 & 2.25 & 2.01 \\
\hline 8 & 0.6 & 80 & 130 & 1.46 & 2.10 & 3.43 & 2.93 & 2.45 & 2.08 & 2.50 & 2.23 & 1.93 & 1.71 \\
\hline 9 & 0.6 & 100 & 150 & 1.55 & 2.51 & 2.82 & 2.35 & 2.22 & 1.86 & 3.31 & 2.94 & 2.53 & 2.14 \\
\hline 10 & 0.6 & 120 & 90 & 1.54 & 1.73 & 2.92 & 2.43 & 2.16 & 1.67 & 1.01 & 0.65 & 0.61 & 0.26 \\
\hline 11 & 1.0 & 30 & 120 & 1.94 & 2.16 & 2.78 & 2.33 & 2.04 & 1.76 & 3.39 & 2.89 & 2.53 & 2.19 \\
\hline 12 & 1.0 & 60 & 130 & 2.25 & 2.55 & 2.84 & 2.50 & 2.20 & 1.81 & 3.50 & 3.08 & 2.74 & 2.35 \\
\hline 13 & 1.0 & 80 & 150 & 2.03 & 2.61 & 3.17 & 2.82 & 2.54 & 2.26 & 3.46 & 3.19 & 2.87 & 2.47 \\
\hline 14 & 1.0 & 100 & 90 & 1.61 & 2.08 & 2.55 & 2.21 & 2.02 & 1.69 & 3.32 & 2.79 & 2.32 & 1.83 \\
\hline 15 & 1.0 & 120 & 110 & 1.99 & 2.55 & 3.00 & 2.62 & 2.36 & 1.79 & 3.37 & 3.02 & 2.47 & 2.05 \\
\hline 16 & 1.5 & 30 & 130 & 1.51 & 2.16 & 3.05 & 2.64 & 2.40 & 2.17 & 3.44 & 3.08 & 2.54 & 2.03 \\
\hline 17 & 1.5 & 60 & 150 & 1.93 & 3.10 & 3.07 & 2.81 & 2.54 & 2.24 & 0.86 & 0.64 & 0.43 & 0.33 \\
\hline 18 & 1.5 & 80 & 90 & 1.52 & 2.16 & 2.76 & 2.43 & 2.09 & 1.61 & 3.08 & 2.57 & 2.04 & 1.40 \\
\hline 19 & 1.5 & 100 & 110 & 1.35 & 1.83 & 3.72 & 3.43 & 2.97 & 2.28 & 3.67 & 3.51 & 3.12 & 2.69 \\
\hline 20 & 1.5 & 120 & 120 & 2.05 & 1.93 & 3.33 & 2.54 & 2.17 & 1.74 & 3.49 & 3.20 & 2.80 & 2.17 \\
\hline 21 & 2.0 & 30 & 150 & 2.45 & 2.51 & 2.84 & 2.26 & 2.02 & 1.60 & 3.49 & 3.23 & 2.89 & 2.34 \\
\hline 22 & 2.0 & 60 & 90 & 1.57 & 1.86 & 2.14 & 1.85 & 1.43 & 1.12 & 3.51 & 3.24 & 2.70 & 1.98 \\
\hline 23 & 2.0 & 80 & 110 & 1.69 & 2.28 & 2.14 & 1.89 & 1.39 & 1.11 & 2.55 & 2.32 & 2.13 & 1.73 \\
\hline 24 & 2.0 & 100 & 120 & 2.19 & 2.67 & 2.31 & 2.00 & 1.69 & 1.50 & 3.60 & 3.47 & 3.05 & 2.68 \\
\hline 25 & 2.0 & 120 & 130 & 2.40 & 2.66 & 2.36 & 2.22 & 1.84 & 1.24 & 3.35 & 3.16 & 2.63 & 1.74 \\
\hline
\end{tabular}

where $n_{\text {rep }}$ is the number of replicates of an experiment (i.e., $n_{\text {rep }}=2$ for this study) and $x_{i}$ is the quality characteristic obtained in the experimental design and used to calculate the $\mathrm{S} / \mathrm{N}$ ratio. The statistical analysis was performed using the results from sorption experiments with both single and binary metal solutions.

In single metallic solutions, the $\mathrm{S} / \mathrm{N}$ ratio analysis was performed using the equilibrium sorption capacity (i.e., $x_{i}=q_{e, i}$ ) of both metals $\mathrm{Cd}^{2+}$ and $\mathrm{Ni}^{2+}$ employing solutions with an initial concentration of $100 \mathrm{mg} / \mathrm{L}$. For the case of binary systems, the $\mathrm{S} / \mathrm{N}$ ratio was calculated using the relationship of sorption capacities $\left(R_{q, i}\right)$.

$R_{q, i}=\left.\frac{q_{e, i}^{\text {binary }}}{q_{e, i}}\right|_{\left[\mathrm{Metal}_{i}\right]_{0}}$

where $q_{e, i}^{\text {binary }}$ is the equilibrium sorption capacity of metal $i$ using a binary solution of metals $\mathrm{A}+\mathrm{B}, q_{e, i}$ is the equilibrium sorption capacity of the metal $i$ using a monocomponent solution with the same initial concentration of the binary metal solution, respectively. The values of $R_{q, i}$ are used to identify the presence of antagonistic or synergistic sorption effects in multi-component solutions (Reynel-Avila et al. 2011). Based on the fact that $\mathrm{Cd}^{2+}$ and $\mathrm{Ni}^{2+}$ ions showed a competitive sorption in binary solutions, it is expected that the values of $R_{q, i}<1.0$ for both metals because the removal performance of the sorbent for each metal ion is lower in binary solution than those obtained for the mono-metallic solution at the same operating conditions (i.e., initial metal concentration, sorbent dosage, $\mathrm{pH}$ and temperature). To improve the sorption properties of the modified-biomass samples, the desirable performance of the sorbent on the simultaneous removal of heavy metals is that $R_{q, i} \rightarrow 1.0$. This condition implies that the uptakes of each metal ion should increase individually, and, at the same time, the antagonistic 
sorption between the two metallic ions should also decrease. It is clear that this is the ideal condition for improving the multicomponent removal performance of modified-biomass samples. Therefore, the results of Taguchi experimental design have been analyzed using the "higher-is-better" quality characteristic to identify the effect of the chemical treatment on the sorption of both heavy metals in single and binary solutions using modifiedBC samples. Herein, it is convenient to recall that several binary solutions with different initial concentrations of both co-ions were used for testing the removal efficacy of treated-biomass samples. So, the following metric was used to calculate the $\mathrm{S} / \mathrm{N}$ ratio for the analysis of sorption data in binary systems.

$R_{q T, i}=\left.\sum_{j=1}^{n_{\text {sol }}} R_{q, i}\right|_{\left[\text {Metal }_{i}\right]_{0, j}}$

where $n_{\text {sol }}=4$ is the number of binary solutions used in removal experiments with a constant initial concentration of the co-ion (i.e., $\mathrm{Cd}^{2+}$ or $\mathrm{Ni}^{2+}$ ) and $R_{q T, i}$ is a parameter used to integrate the overall removal performance of chemically treated-biomass samples in binary metal systems. Note that this parameter is used to consider the effect of co-ion concentration on the data analysis of the chemical modification procedure. In summary, the statistical analysis of binary removal experiments was performed using $x_{i}=R_{q T, i}$ for the calculation of $\mathrm{S} / \mathrm{N}$ ratio.

Finally, the variance analysis on the $\mathrm{S} / \mathrm{N}$ ratios was performed using the next equations.

$$
\begin{aligned}
& \mathrm{SS}_{T}=\left[\sum_{i=1}^{n_{\mathrm{dat}}} y_{i}^{2}\right]-\frac{T_{t}^{2}}{n_{\mathrm{dat}}} \\
& \mathrm{SS}_{F}=\left[\sum_{i=1}^{k_{F}}\left(\frac{F_{i}^{2}}{n_{F_{i}}}\right)\right]-\frac{T_{t}^{2}}{n_{\mathrm{dat}}} \\
& \sigma_{F}=\frac{\mathrm{SS}_{F}}{v_{F}}
\end{aligned}
$$

where $n_{\mathrm{dat}}$ is the total number of experimental data, $n_{F i}$ is the number of observations under the level $i, F_{i}$ is obtained from the sum of observations under the level $i, T_{t}$ is the sum of all observations, $y_{i}$ is the value of the $\mathrm{S} / \mathrm{N}$ ratio, $\mathrm{SS}_{T}$ is the total sum of squares, $k_{F}$ is the number of levels of factor $F, v_{F}$ is the degrees of freedom of factor $F$ (i.e., $k_{F}-1$ ), $\sigma_{F}$ is the variance for factor $F$ and $\mathrm{SS}_{F}$ is the sum of squares for factor $F$, respectively. Statistical analysis was performed using Excel solver ${ }^{\circledR}$, and the best operating conditions of the chemical treatment using citric acid were identified for obtaining $q_{e, i} \uparrow$ and $R_{q T, i} \uparrow$ for both metallic ions in single and binary solutions.

Finally, the sorption selectivity $\left(S_{A / B}\right)$ of tested heavy metals on treated-biomass samples in binary solutions was also calculated and used for sorption data analysis.
$S_{\mathrm{Cd}^{2+} / \mathrm{Ni}^{2+}}=\frac{q_{e, \mathrm{Cd}^{2+}}}{q_{e, \mathrm{Ni}^{2+}}}$

where $q_{e, i}$ is given in $\mathrm{mmol} / \mathrm{g}$. This parameter has been used to identify the affinity of the modified-biomass samples for a specific pollutant in the binary metal solution.

\section{Results and discussion}

Results of the chemical modification of BC biomass surface and its removal performance

Table 1 shows the results obtained using the modified-BC samples prepared with the Taguchi experimental design $\mathrm{L}_{25}$ and the single metal solutions. Raw BC biomass showed maximum metal sorption capacities of 1.71 and $0.95 \mathrm{mg} / \mathrm{g}$ for $\mathrm{Cd}^{2+}$ and $\mathrm{Ni}^{2+}$ ions at $30{ }^{\circ} \mathrm{C}$ and $\mathrm{pH} 5$, respectively. However, the modified samples showed better sorption capacities than the raw BC biomass. Specifically, the sorption properties of treated-BC samples may increase up to 81.0 and $158.0 \%$ for $\mathrm{Cd}^{2+}$ and $\mathrm{Ni}^{2+}$ ions in single metal solutions. As expected, all modified-BC samples showed different metal uptakes depending on the conditions used for the chemical modification process. On the other hand, the multicomponent sorption capacities of both raw and modified-BC samples in binary solutions were lower than those obtained in the single metal solution with the same initial concentration, see results reported in Table 1. In fact, the metal removal performance of all treated-biomass samples decreased when the initial co-ion concentration increased in the binary metal solution. These results confirmed that there is a competitive sorption (i.e., antagonistic sorption) in the simultaneous removal of these heavy metal ions. Note that the co-ion concentration increased the magnitude of antagonistic sorption in binary systems, see results reported in Table 1 .

With illustrative purposes, Fig. 3 shows the equilibrium metal uptakes of raw biomass and selected treated-BC samples using binary solutions. Overall, the reduction in metal uptakes in binary metal systems ranged from 7.5 to $75.0 \%$ for $\mathrm{Cd}^{2+}$ and from 8.5 to $97.4 \%$ for $\mathrm{Ni}^{2+}$ in all biomass samples. The calculated values of $R_{q}$ for tested heavy metals are $<1$ in all binary systems, see Fig. 4 . In particular, the performance of modified samples for $\mathrm{Ni}^{2+}$ removal is more sensitive to the operating conditions of the chemical modification using citric acid. It is convenient to remark that previous studies have reported these competitive sorption effects between these heavy metal ions using different natural and synthetic sorbents (Srivastava et al. 2007, 2008, 2009; Reynel-Avila et al. 2011). This removal behavior is commonly attributed to the competition of co-ions for the sorption sites on the material surface. 

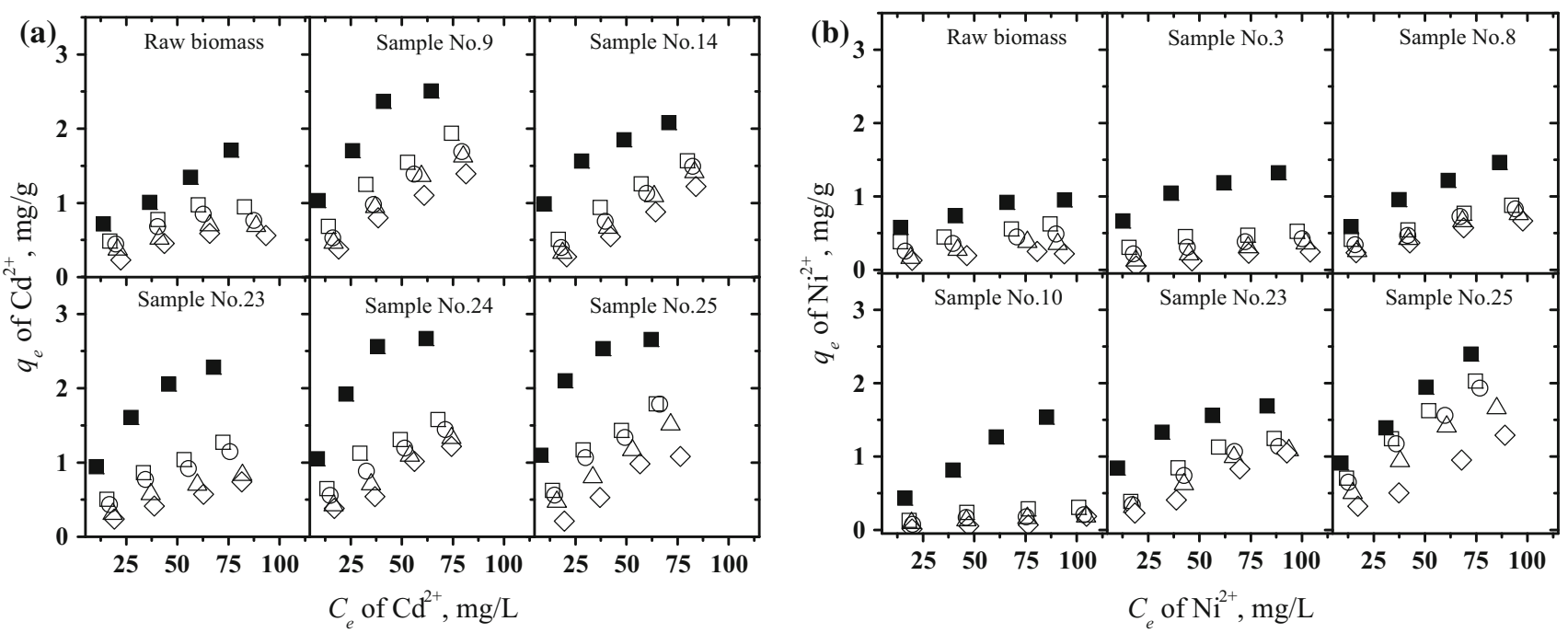

Fig. 3 Multicomponent removal performance for $\mathbf{a} \mathrm{Cd}^{2+}$ and $\mathbf{b ~} \mathrm{Ni}^{2+}$ ions using modified-BC samples. Initial concentration of co-ion $\mathrm{Ni}^{2+}$ or $\mathrm{Cd}^{2+}$ : filled square 0 , open square 25 , circle 50 , triangle 75 and diamond $100 \mathrm{mg} / \mathrm{L}$

However, it appears that the presence of $\mathrm{Cd}^{2+}$ ions in the binary solution has a major effect on the sorption of $\mathrm{Ni}^{2+}$ ions using modified-BC samples. For example, in the case of modified sample No. 10, the removal performance for $\mathrm{Ni}^{2+}$ ions decreased significantly (i.e., $R_{q}<0.4$ ) in all sorption experiments performed with different initial concentrations of the co-ion (i.e., $\mathrm{Cd}^{2+}$ ) in binary mixtures. Similar results have been obtained for the 25 biomass samples obtained from the Taguchi experimental design $\mathrm{L}_{25}$. In general, the metal affinity order is $\mathrm{Cd}^{2+}>\mathrm{Ni}^{2+}$ and is in accordance with a decreasing ionic radius $\left(\mathrm{Cd}^{2+}\right.$ : $0.97 \AA$ and $\mathrm{Ni}^{2+}: 0.694 \AA$ ) and covalent radius $\left(\mathrm{Cd}^{2+}\right.$ : $1.48 \AA$ and $\mathrm{Ni}^{2+}: 1.21 \AA$ ). Similar trends have been reported for other sorbents used in the simultaneous removal of both heavy metal ions, e.g., green alga (Aksu and Donmez 2006), chicken feathers (Reynel-Avila et al. 2012) and tourmaline (Liu et al. 2013).

On the other hand, Fig. 5 shows the sorption selectivity obtained for different treated-biomass samples, and these results confirmed that the sorption of $\mathrm{Cd}^{2+}$ is preferred over $\mathrm{Ni}^{2+}$ in binary metal systems. Specifically, the modified-BC samples showed a greater affinity for $\mathrm{Cd}^{2+}$ ion in all sorption experiments. It is interesting to highlight that the operating conditions of the chemical modification with citric acid have a significant impact on the multicomponent removal performance of treated-biomass samples. In general, these results indicated that the reactions between citric acid and the biomass can be controlled to improve the uptake properties of $\mathrm{BC}$ biomass for the removal of heavy metals even under conditions of competitive sorption (i.e., simultaneous removal of several pollutants in the solution).
Statistical analysis of the $\mathrm{S} / \mathrm{N}$ ratios for the chemical modification of $\mathrm{BC}$ using citric acid

Figure 6 shows the mean S/N ratios calculated from the removal experiments using both single and binary metal solutions. In these plots, an increment in the value of $\mathrm{S} / \mathrm{N}$ ratios indicates a better removal performance and the operating conditions that cause the best improvement in these ratios should be considered as the optimal conditions for the chemical treatment using citric acid. For single metallic solutions, it is clear that the metal-binding properties of treated-biomass samples increase with both the citric acid concentration and the temperature of thermal treatment. During the chemical treatment, the citric acid when heated will dehydrate to yield a reactive anhydride and this anhydride can react with the biomass introducing acidic groups on the surface of BC endocarp (Wing 1996; Marshall et al. 1999; Altun and Pehlivan 2012; LeyvaRamos et al. 2012). Therefore, the metal uptakes of treatedBC samples are enhanced if a higher citric acid concentration is used. This improvement in the removal performance of the biomass is related to the increment on the content of acidic sites. Figure 1e shows that the content of acidic sites of all treated-BC endocarp samples is higher than that obtained for raw BC sample (i.e., $10.03 \mathrm{mmol} / \mathrm{g}$ ), and the modified-biomass samples showed an increment in the total acidic sites with the citric acid concentration used in the chemical modification. The citric acid treatment may increase the quantity of acidic sites up to $11 \%$ in the biomass. However, an acid concentration of $1.0 \mathrm{M}$ is a suitable value for the chemical modification process because higher acid concentrations do not improve 
(a) Raw biomass
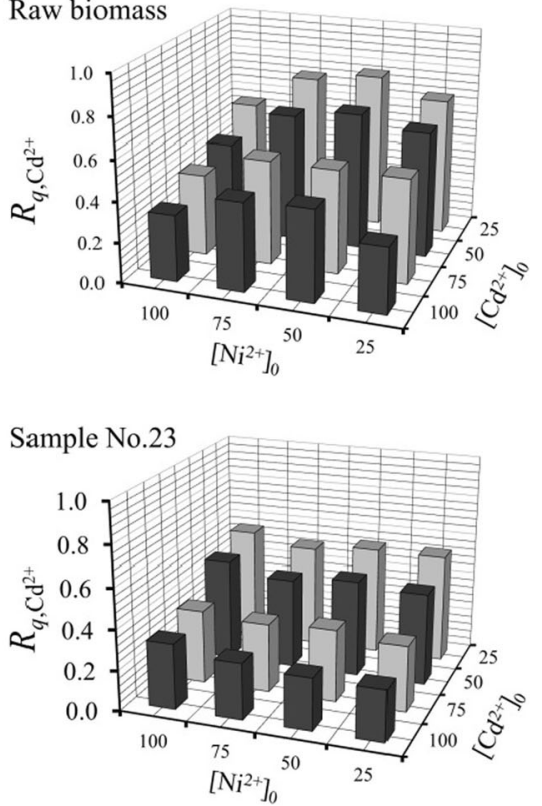

(b) Raw biomass
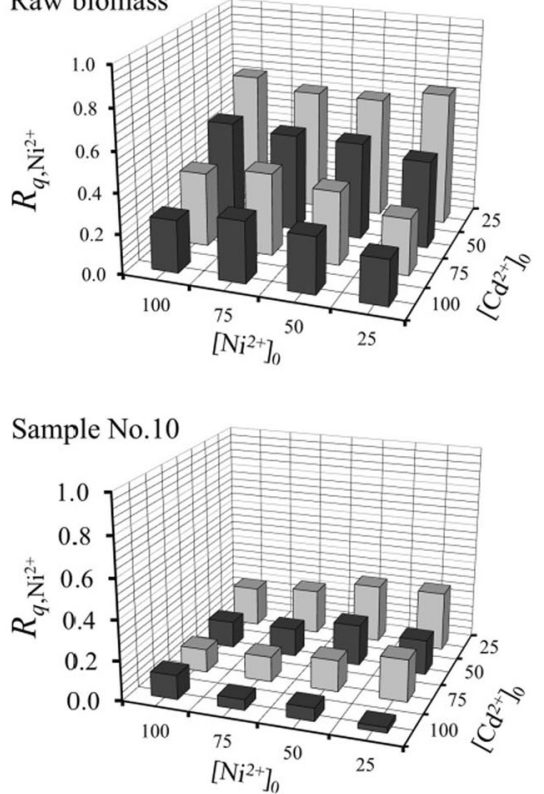

Sample No.9

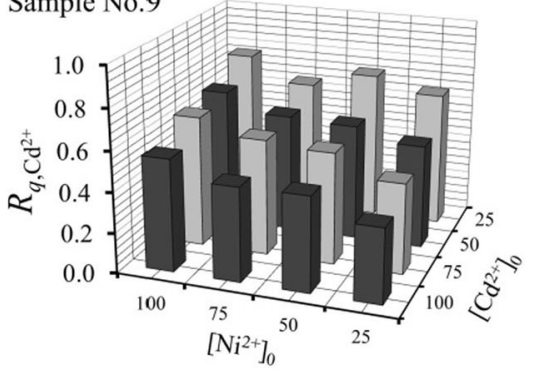

Sample No. 24

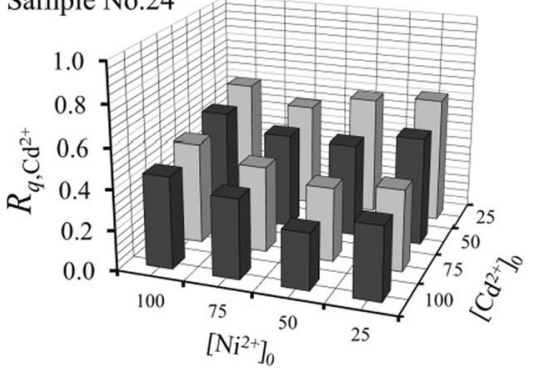

Sample No.3

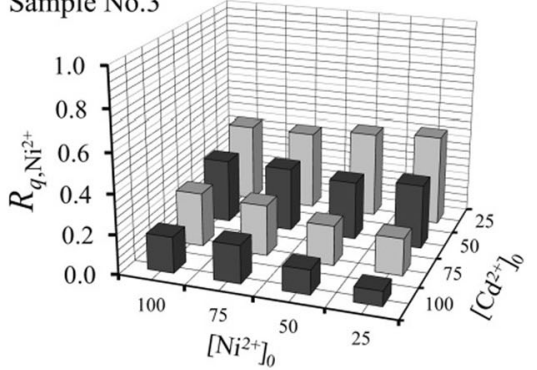

Sample No.23

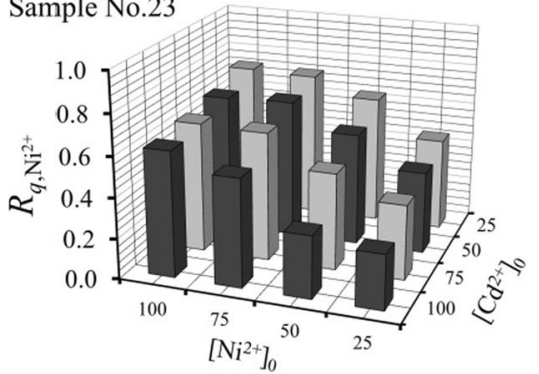

Sample No.14

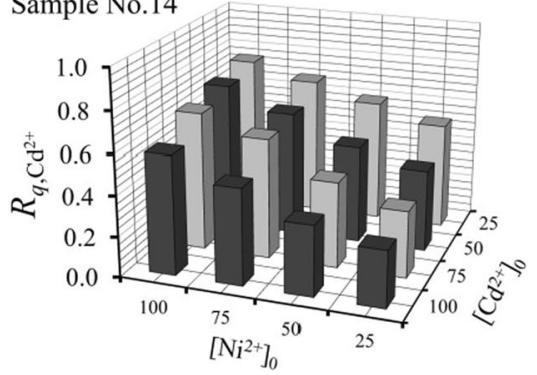

Sample No. 25

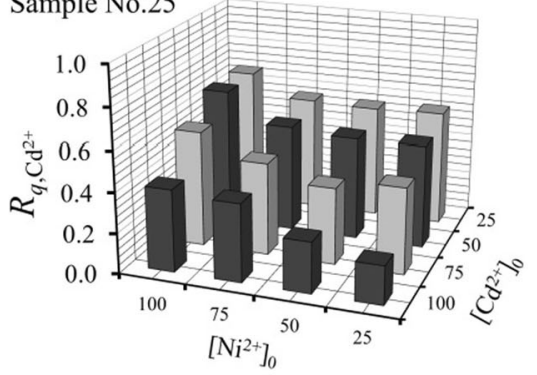

Sample No.8

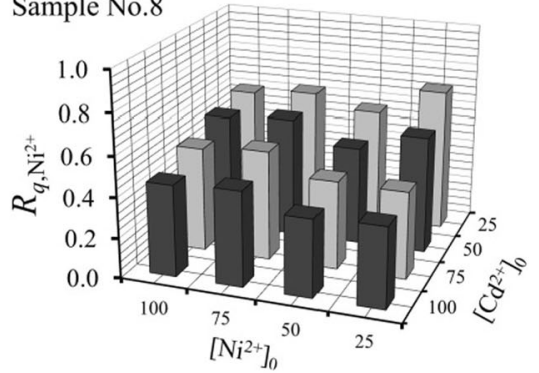

Sample No.25

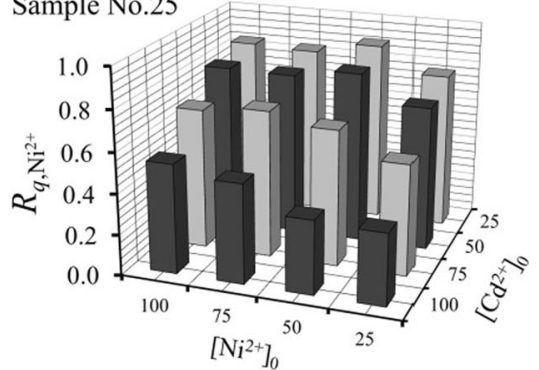

Initial concentration of binary metal solution, $\mathrm{mg} / \mathrm{L}$

Fig. $4 R_{q}$ for the multicomponent removal of $\mathbf{a ~} \mathrm{Cd}^{2+}$ and $\mathbf{b ~ N i}{ }^{2+}$ ions in binary systems using modified-biomass samples

significantly the sorption properties of treated biomass. This citric acid concentration is consistent with results of previous studies (e.g., Marshall et al. 1999; Leyva-Ramos et al. 2012), which have reported that an acid concentration from 0.6-1.0 $\mathrm{M}$ is optimum for improving the performance of lignocellulosic biomasses for the heavy metal removal. Additionally, results also show that the temperature of chemical treatment is a relevant parameter for enhancing the metal uptakes of BC endocarp. Note that the temperature increment of the chemical modification process may increase the possibility of the cross-linking between two cellulosic molecules of BC endocarp (Altun and Pehlivan 2012). In fact, these results suggest that the reaction between citric acid and this biomass is an endothermic process.

For the case of binary mixtures, the same trends for the effect of operating variables on the removal performance of modified samples were observed, see Fig. 6. It is 

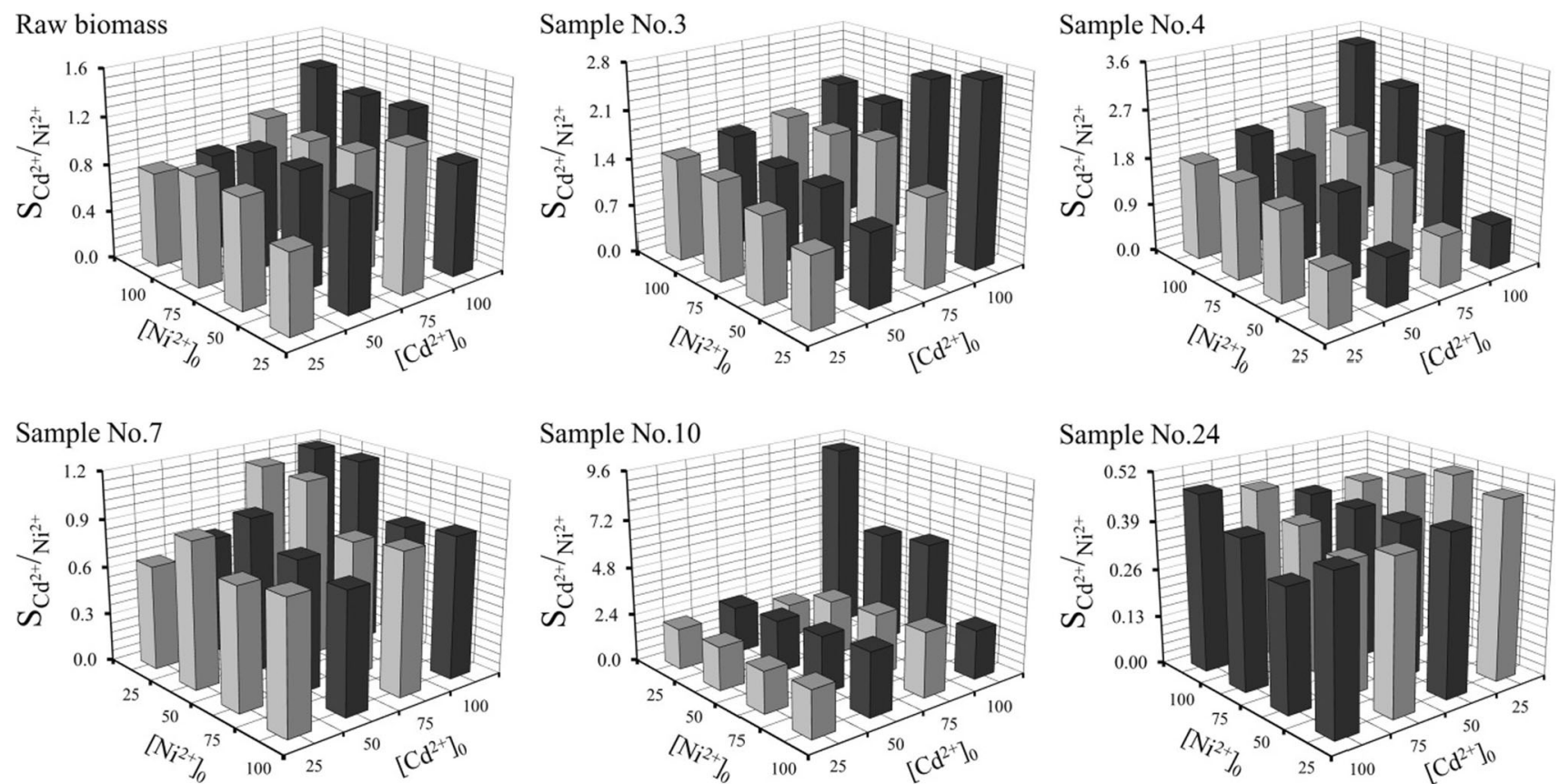

Initial concentration of binary metal solution, $\mathrm{mg} / \mathrm{L}$

Fig. 5 Sorption selectivity $\left(S_{C d / N i}\right)$ of $\mathrm{Cd}^{2+}$ and $\mathrm{Ni}^{2+}$ ions in binary systems using modified-biomass samples

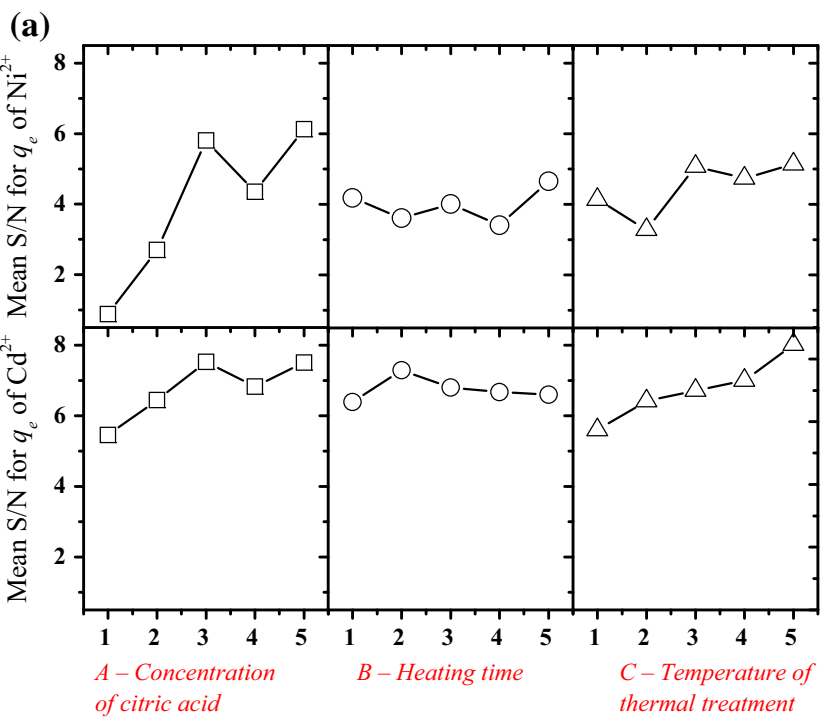

Operating variable

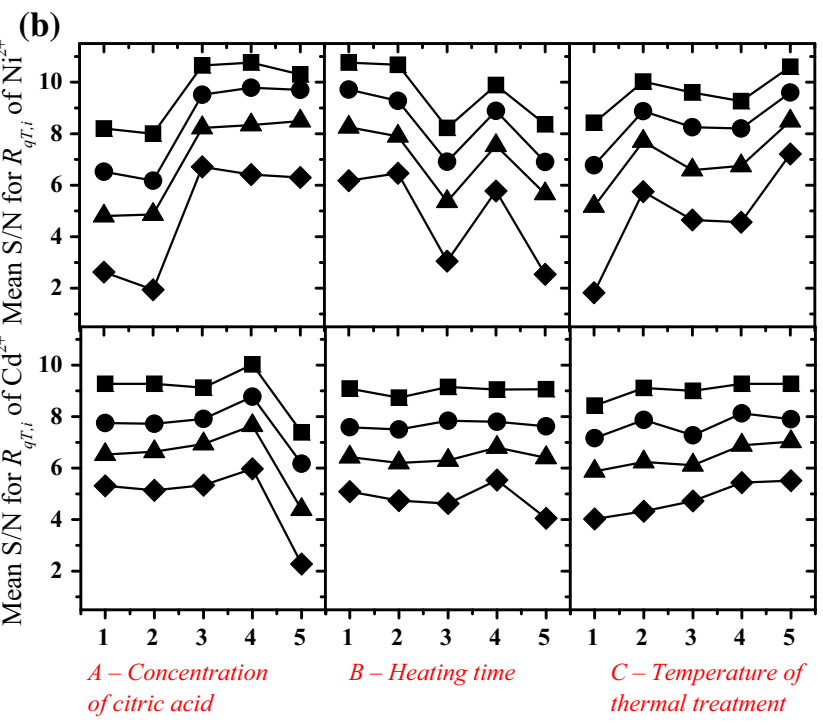

Operating variable

Fig. 6 Mean $\mathrm{S} / \mathrm{N}$ ratio calculated using a single metal solutions and $\mathbf{b}$ binary $\mathrm{Cd}^{2+}-\mathrm{Ni}^{2+}$ solutions. Initial concentration of co-ion: filled square 25 , filled circle 50, filled triangle 75 and filled diamond $100 \mathrm{mg} / \mathrm{L}$

interesting to comment that the initial co-ion concentration does not alter the trends observed for the studied variables of the chemical modification treatment. In fact, the plots obtained for the $\mathrm{S} / \mathrm{N}$ ratios at different co-ion concentrations could be considered parallels. This result is relevant from a practical point of view because the optimization of operating conditions of the chemical modification of the biomass can be performed either using mono-metallic or binary metal solutions, thus assuring that the best conditions for the treatment of biomass samples can be identified without concerning of the type of solution used in sorption experiments. However, it is important to recall that the 
Table 2 Statistical analysis of $\mathrm{L}_{25}$ experimental design used for the $\mathrm{BC}$ chemical treatment. Sorption experiments with single and binary metal solutions of $\mathrm{Cd}^{2+}$ and $\mathrm{Ni}^{2+}$

\begin{tabular}{|c|c|c|c|c|c|c|c|c|c|c|}
\hline \multirow[t]{3}{*}{ Factor $^{1}$} & \multicolumn{4}{|c|}{ Statistical analysis of $\mathrm{S} / \mathrm{N}$ ratio for } & \multirow[t]{3}{*}[\mathrm{B}^{2+}]{$_{0}, \mathrm{mg} / \mathrm{L}^{2}$} & \multirow[t]{3}{*}{ Factor $^{1}$} & \multicolumn{4}{|c|}{ Statistical analysis of $\mathrm{S} / \mathrm{N}$ ratio for } \\
\hline & \multicolumn{2}{|l|}{$\mathrm{Cd}^{2+}$} & \multicolumn{2}{|l|}{$\mathrm{Ni}^{2+}$} & & & \multicolumn{2}{|l|}{$\overline{\mathrm{Cd}^{2+}}$} & \multicolumn{2}{|l|}{$\mathrm{Ni}^{2+}$} \\
\hline & $\mathrm{SS}_{\mathrm{F}}$ & $\sigma_{\mathrm{F}}$ & $\mathrm{SS}_{\mathrm{F}}$ & $\sigma_{\mathrm{F}}$ & & & $\mathrm{SS}_{\mathrm{F}}$ & $\sigma_{\mathrm{F}}$ & $\mathrm{SS}_{\mathrm{F}}$ & $\sigma_{\mathrm{F}}$ \\
\hline A & 14.86 & 3.72 & 96.35 & 24.09 & 25 & A & 19.00 & 4.75 & 37.47 & 9.37 \\
\hline B & 2.23 & 0.56 & 4.84 & 1.21 & & B & 0.53 & 0.13 & 30.01 & 7.50 \\
\hline \multirow[t]{10}{*}{$\mathrm{C}$} & 15.54 & 3.88 & 12.02 & 3.01 & & $\mathrm{C}$ & 2.52 & 0.63 & 13.33 & 3.33 \\
\hline & & & & & 50 & A & 17.74 & 4.44 & 66.29 & 16.57 \\
\hline & & & & & & B & 0.43 & 0.11 & 35.93 & 8.98 \\
\hline & & & & & & $\mathrm{C}$ & 3.58 & 0.89 & 21.89 & 5.47 \\
\hline & & & & & 75 & A & 30.02 & 7.50 & 74.71 & 18.68 \\
\hline & & & & & & B & 1.02 & 0.25 & 35.47 & 8.87 \\
\hline & & & & & & $\mathrm{C}$ & 5.02 & 1.26 & 31.23 & 7.81 \\
\hline & & & & & 100 & A & 42.12 & 10.53 & 107.15 & 26.79 \\
\hline & & & & & & B & 6.10 & 1.53 & 68.63 & 17.16 \\
\hline & & & & & & $\mathrm{C}$ & 8.72 & 2.18 & 78.04 & 19.51 \\
\hline
\end{tabular}

${ }^{1}$ Variables of the chemical modification process: A-concentration of citric acid, B-heating time and $\mathrm{C}$ - temperature of thermal treatment

${ }^{2}$ Initial co-ion concentration in binary solution $\mathrm{A}^{2+}-\mathrm{B}^{2+}$

effect of operating variables on the sorption properties of modified samples can be easily identified if binary solutions with higher co-ion concentration are employed. So, the presence of a higher content of co-ion is useful to observe and identify clearly the trends between the changes in the operating conditions of chemical modification and the metal removal performance of the treated biomass.

Statistical analysis of $\mathrm{L}_{25}$ experimental design is reported in Table 2. ANOVA analysis confirmed that the citric acid concentration and the temperature of thermal treatment are the main variables for improving the sorption properties of biomass samples. For the case of $\mathrm{Ni}^{2+}$ removal in binary systems, the heating time appears to be a relevant operating factor for improving the metal uptakes, see results reported in Fig. 6 and Table 2. Based on the results of ANOVA analysis, the best operating conditions for the surface chemical modification of BC samples have been identified: a) citric acid concentration $=1.0 \mathrm{M}$, b) heating time $=60 \mathrm{~min}$ and $\mathrm{c}$ ) temperature of thermal treatment $=150{ }^{\circ} \mathrm{C}$. This new treated-biomass sample (i.e., sample No. 26) was prepared, and Fig. 7 shows its removal performance including $R_{q}$ and $S_{\mathrm{Cd} / \mathrm{Ni} \text {. This bio- }}$ mass sample showed the highest metal uptakes and a balanced removal selectivity for both $\mathrm{Ni}^{2+}$ and $\mathrm{Cd}^{2+}$ ions. In fact, the antagonistic sorption effects caused by both coions are reduced significantly for this treated biomass, and there is a proper trade-off for the simultaneous removal of both metallic ions. In particular, the concentration effect of co-ion $\mathrm{Cd}^{2+}$ on the $\mathrm{Ni}^{2+}$ removal is reduced significantly (i.e., the values of $R_{q}$ increased), and the modified-biomass sample showed higher $\mathrm{Ni}^{2+}$ uptakes than the raw biomass and samples prepared from the experimental design $L_{25}$. Therefore, these conditions of the chemical modification can be considered as the best conditions for improving the removal performance of $\mathrm{BC}$ endocarp.

Finally, the binary sorption data of the best modified sample were modeled using the non-modified Langmuir, extended Langmuir and non-modified Sips isotherm models. Results of data fitting and the parameters of tested models are reported in Table 3. In general, non-modified Sips model offers the best performance for fitting sorption data obtained in this study.

Characterization of raw and modified-biomass samples and the mechanism involved in the sorption of heavy metals from aqueous solution

BC endocarp is a lignocellulosic biomass mainly constituted by natural polymers, and its composition includes: cellulose $(42.4 \%)$, hemicellulose $(10.5 \%)$, lignin $(36.7 \%)$ and soluble compounds $(10.3 \%)$. These organic constituents have functional groups (e.g., carboxyl, hydroxyl, phenolic), which have been recognized to participate in heavy metal removal from water $(\mathrm{Lu}$ et al. 2009). With illustrative purposes, Fig. 1b, c show the SEM images and results of EDX analysis of BC endocarp 
Fig. 7 Removal performance of the best modified-BC sample. Initial concentration of co-ion: filled square 0 , open square 25 , circle 50, triangle 75 and diamond $100 \mathrm{mg} / \mathrm{L}$
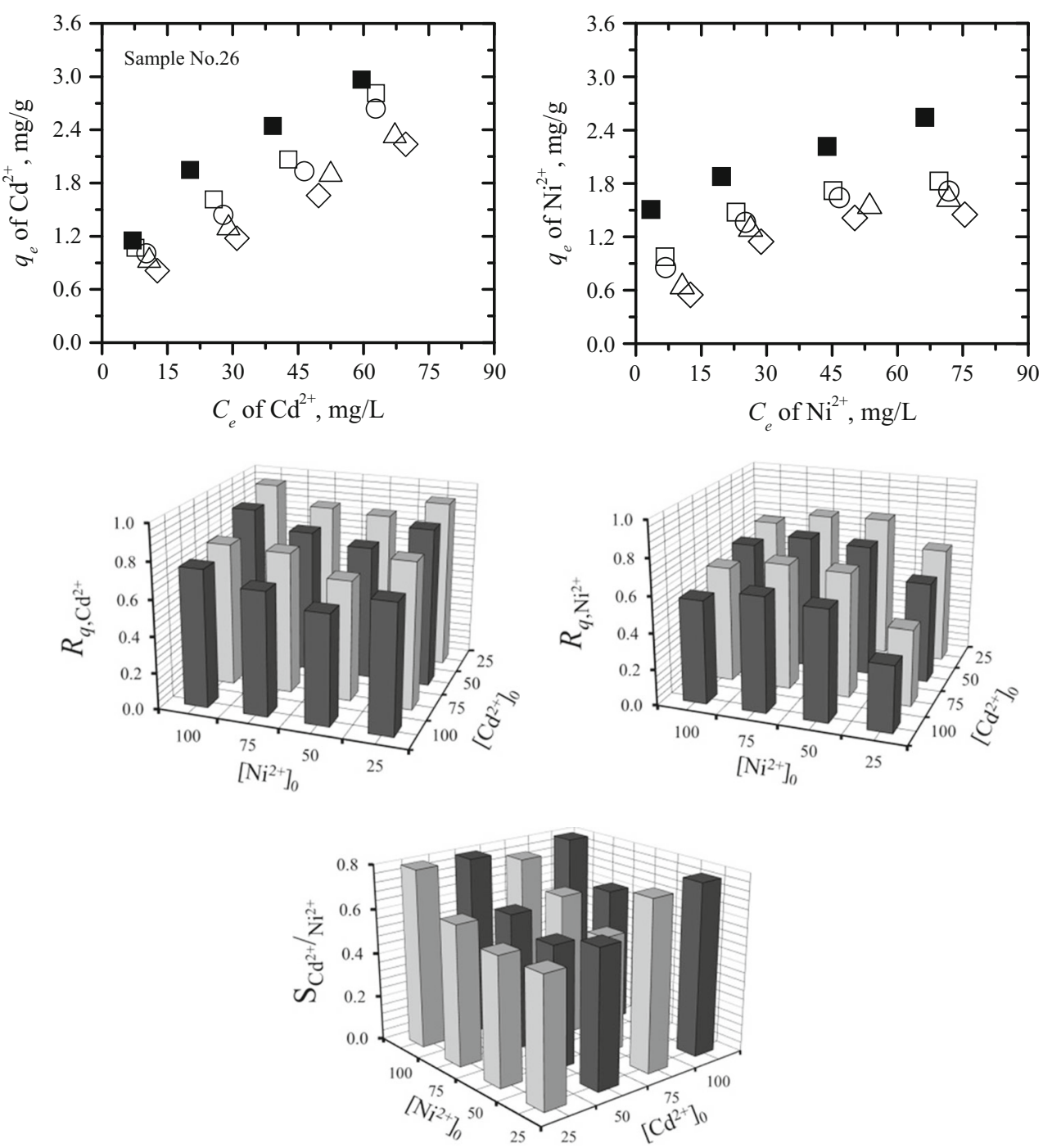

Initial metal concentration of binary solution, $\mathrm{mg} / \mathrm{L}$

samples. EDX analysis indicated the presence of carbon, oxygen and calcium as the main elements of the biomass composition, while X-ray diffraction pattern of $\mathrm{BC}$ endocarp confirmed the presence of hydrated calcium oxalate in this lignocellulosic material (see Fig. 1d).

FT-IR spectra of raw and selected modified-biomass samples are reported in Fig. 1f. These spectra confirmed the presence of the well-known functional groups of lignocellulosic biomasses. Specifically, FTIR spectra of raw and modified biomass are similar in the fingerprint region of 4,000-700 $\mathrm{cm}^{-1}$. All samples showed the characteristic band of the $\mathrm{O}-\mathrm{H}$ vibrations of hydroxyl groups at $\sim 3,400 \mathrm{~cm}^{-1}$, which is related to alcohols, phenols and carboxylic acids of cellulose and lignin (Iqbal et al. 2009). The band located at $\sim 2,900 \mathrm{~cm}^{-1}$ can be assigned to the $\mathrm{C}-\mathrm{H}$ stretching of aromatic hydrocarbons, while the peak at
$1,735 \mathrm{~cm}^{-1}$ corresponds to the $\mathrm{C}=\mathrm{O}$ stretching vibrations of carbonyl groups (Leyva-Ramos et al. 2012). The $\mathrm{C}=\mathrm{C}$ stretching bands for aromatic rings are located at 1,600 and $1,500 \mathrm{~cm}^{-1}$ and the peak located at $\sim 1,035 \mathrm{~cm}^{-1}$ corresponds to the $\mathrm{C}-\mathrm{O}$ stretching band, which is associated to the natural polymer content of the BC endocarp (Zhu et al. 2008; Leyva-Ramos et al. 2012; Sena Neto et al. 2013). In addition, FT-IR spectra showed the bands corresponding to the hydrated calcium oxalate. Specifically, the peaks for the asymmetric and symmetric stretch of the coordinated water molecules are exhibited above $3,400 \mathrm{~cm}^{-1}$, the out-ofplane bending mode of water at $781 \mathrm{~cm}^{-1}$, and the $\mathrm{O}-\mathrm{C}-\mathrm{O}$ in-plane bending mode at $518 \mathrm{~cm}^{-1}$. The main antisymmetric carbonyl stretching band (COO-) specific to the oxalate family occurs at $1,618 \mathrm{~cm}^{-1}$, while the secondary carbonyl stretching band, the metal-carboxylate stretch 
Table 3 Results of data fitting for the simultaneous removal of $\mathrm{Cd}^{2+}$ and $\mathrm{Ni}^{2+}$ ions using the best modified-BC sample

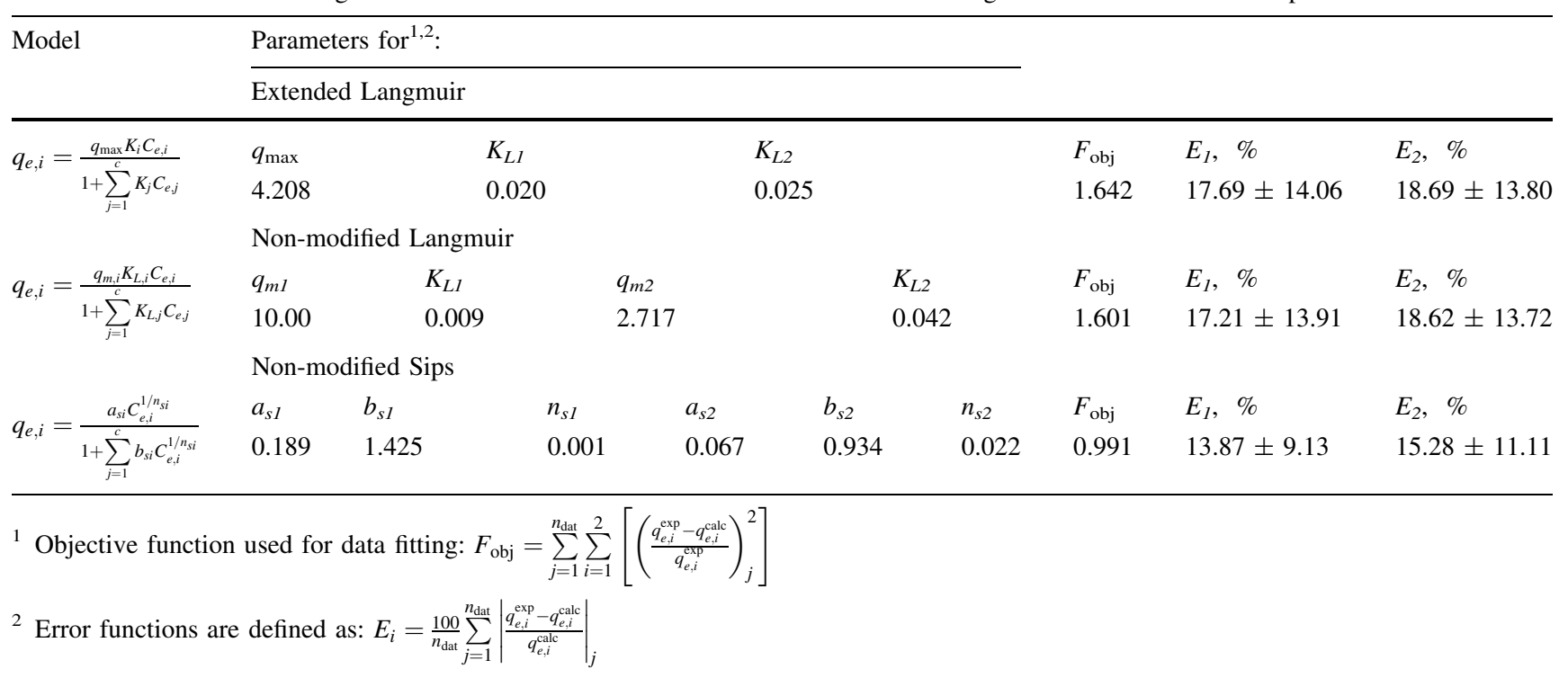

(COO-), can be located at $1,317 \mathrm{~cm}^{-1}$ (Ouyang et al. 2003). For treated-biomass samples, the increase in the carbonyl $(\mathrm{C}=\mathrm{O})$ vibration absorbance $\left(1,730-1,750 \mathrm{~cm}^{-1}\right)$ and the broad adsorption peaks in the hydroxyl $(\mathrm{O}-\mathrm{H})$ stretching band $\left(3,430-3,440 \mathrm{~cm}^{-1}\right)$ are associated with the citric acid esterification (Zhu et al. 2008; Altun and Pehlivan 2012). These results confirmed that the citric acid chemical modification introduces additional acidic groups to the BC endocarp samples, and, consequently, it increased the metal-binding capacities of these materials. In addition, this chemical treatment may increase the accessibility and the degree of protonation of functional groups on the biomass (Sajab et al. 2011).

In particular, the phenolic, carboxylic and hydroxyl groups of lignocellulosic biomasses may interact with heavy metal ions via the next reactions (Garcia-Reyes et al. 2009; Tan et al. 2010; Leyva-Ramos et al. 2012).

$$
\begin{aligned}
& 2(\equiv \mathrm{S}-\mathrm{OH})+\mathrm{M}^{2+} \rightarrow(\equiv \mathrm{S}-\mathrm{O})_{2} \mathrm{M}+2 \mathrm{H}^{+} \\
& 2(\equiv \mathrm{S}-\mathrm{COOH})+\mathrm{M}^{2+} \rightarrow(\equiv \mathrm{S}-\mathrm{COO})_{2} \mathrm{M}+2 \mathrm{H}^{+} \\
& 2\left(\equiv \mathrm{S}-\mathrm{C}_{6} \mathrm{H}_{5}-\mathrm{OH}\right)+\mathrm{M}^{2+} \\
& \rightarrow\left(\equiv \mathrm{S}-\mathrm{C}_{6} \mathrm{H}_{5}-\mathrm{O}\right)_{2} \mathrm{M}+2 \mathrm{H}^{+}
\end{aligned}
$$

where $\mathrm{M}^{2+}$ corresponds to the heavy metal ion involved in the removal process and $\mathrm{S}$ represents the biomass surface. Herein, it is convenient to remark that the speciation diagrams for metal solutions at tested experimental conditions were calculated using the software MINTEQA2, which showed that free $\mathrm{Cd}^{2+}$ and $\mathrm{Ni}^{2+}$ ions were the predominant species at $\mathrm{pH}$ 5. The removal mechanism given by Eqs. (9)-(11) is consistent with the results of FT-IR spectra where those samples with more acidic sites showed a better sorption performance. Note that the results of this study showed that the solution $\mathrm{pH}$ decreased in all removal experiments during the sorption of both heavy metals with modified-biomass samples. Therefore, the reduction in $\mathrm{pH}$ could be attributed to the release of $\mathrm{H}^{+}$from biomass surface during the metal ion exchange mechanism. Additionally, an ionic exchange involving $\mathrm{Ca}^{2+}$ ions could also occur during the heavy metal removal.

$(\equiv \mathrm{S}-\mathrm{COO})_{2} \mathrm{Ca}+\mathrm{M}^{2+} \rightarrow(\equiv \mathrm{S}-\mathrm{COO})_{2} \mathrm{M}+\mathrm{Ca}^{2+}$

This exchange process involved in the metal uptake has been documented for others biomasses containing pectin and hemi-celluloses, which show carboxyl groups linked together by calcium bridges (Garcia-Reyes et al. 2009; Iqbal et al. 2009). As stated, EDX analysis indicated that a significant content of calcium is present in BC endocarp, and results showed that $\mathrm{Ca}^{2+}$ was released during the heavy metal removal using raw and treated-biomass samples. In summary, the mechanism for the sorption of heavy metals using modified-biomass samples could be an ion exchange process where both the interactions with phenolic, carboxylic and hydroxyl groups of the sorbent surface and the replacement of $\mathrm{Ca}^{2+}$ may be involved.

\section{Conclusion}

Sorption properties of BC biomass for heavy metal removal from water have been studied using a surface 
chemical modification process using citric acid. In particular, the sorption capacities and selectivity for the uptake of $\mathrm{Cd}^{2+}$ and $\mathrm{Ni}^{2+}$ ions in both single and binary metal solutions have been improved and optimized using a statistical analysis based on the $\mathrm{S} / \mathrm{N}$ ratios. A special attention has been given to reduce the competitive sorption effects caused by $\mathrm{Cd}^{2+}$ ions on the $\mathrm{Ni}^{2+}$ removal using modifiedbiomass samples in binary systems. Results indicated that it is feasible to improve the uptakes of these metal ions in both types of solutions and thus reducing the competitive sorption and increasing the metal selectivity during the simultaneous removal of $\mathrm{Cd}^{2+}$ and $\mathrm{Ni}^{2+}$. In particular, binary solutions with high co-ion concentrations are useful to identity the trends and effect of the operating variables of the chemical modification process on the sorption properties of this biomass. The improved metal sorption properties are mainly associated with an increment in the oxygenated functional groups on the biomass surface caused by the acid treatment. The proposed methodology can be extended for development selective sorbents for the treatment and purification of wastewaters polluted by several compounds.

Acknowledgments Authors acknowledge the financial support provided by CONACYT, DGEST and Instituto Tecnológico de Aguascalientes.

\section{References}

Aksu Z, Donmez G (2006) Binary biosorption of cadmium(II) and nickel(II) onto dried Chlorella vulgaris: co-ion effect on monocomponent isotherm parameters. Process Biochem 41:860-868

Altun T, Pehlivan E (2012) Removal of $\mathrm{Cr}(\mathrm{VI})$ from aqueous solutions by modified walnut shells. Food Chem 132:693-700

Garcia-Reyes RB, Rangel-Mendez JR, Alfaro-De la Torre MC (2009) Chromium(III) uptake by agro-waste biosorbents: chemical characterization, sorption-desorption studies and mechanism. J Hazard Mater 170:845-854

Gong R, Jin Y, Sun J, Zhong K (2008) Preparation and utilization of rice straw bearing carboxyl groups for removal of basic dyes from aqueous solution. Dyes Pigments 76:519-524

Iqbal M, Saeed A, Zafar SI (2009) FTIR spectrophotometry, kinetics and adsorption isotherms modeling ion exchange, and EDX analysis for understanding the mechanism of $\mathrm{Cd}^{2+}$ and $\mathrm{Pb}^{2+}$ removal by mango peel waste. J Hazard Mater 164:161-171

Leyva-Ramos R, Bernal-Jacome LA, Acosta-Rodríguez I (2005) Adsorption of cadmium(II) from aqueous solution on natural and oxidized corncob. Sep Purif Technol 45:41-49

Leyva-Ramos R, Landin-Rodriguez LE, Leyva-Ramos S, MedellinCastillo NA (2012) Modification of corncob with citric acid to enhance its capacity for adsorbing cadmium(II) from water solution. Chem Eng J 180:113-120

Liu H, Wang C, Liu J, Wang BL, Sun H (2013) Competitive adsorption of $\mathrm{Cd}(\mathrm{II}), \mathrm{Zn}(\mathrm{II})$ and $\mathrm{Ni}(\mathrm{II})$ from their binary and ternary acidic systems using tourmaline. J Environ Manag 128:727-734

Lu D, Cao Q, Li X, Cao X, Luo F, Shao W (2009) Kinetics and equilibrium of $\mathrm{Cu}(\mathrm{II})$ adsorption onto chemically modified orange peel cellulose biosorbents. Hydrometallurgy 95:145-152
Marshall WE, Wartelle LH, Boler DE, Johns MM, Toles CA (1999) Enhanced metal adsorption by soybean hulls modified with citric acid. Bioresour Technol 69:263-268

Medina-Torres R, Salazar-Garcia S, Gomez-Aguilar JR (2004) Fruit quality indices in eight nance [Byrsonima crassifolia (L.) H.B.K.] selections. HortScience 39:1070-1073

Ngah WSW, Hanafiah MAKM (2008) Removal of heavy metal ions from wastewater by chemically modified plant wastes as adsorbents: a review. Bioresour Technol 99:3935-3948

Ouyang JM, Duan L, Tieke B (2003) Effects of carboxylic acids on the crystal growth of calcium oxalate nanoparticles in lecithinwater liposome systems. Langmuir 19:8980-8985

Perez-Gutierrez RM, Muñiz-Ramirez A, Gomez YG, Ramirez EB (2010) Antihyperglycemic, antihyperlipidemic and antiglycation effects of Byrsonima crassifolia fruit and seed in normal and streptozotocin-induced diabetic rats. Plant Food Hum Nutr 65:350-357

Reddad Z, Gerente C, Andres Y, Ralet MC, Thibault JF, Cloirec PL (2002) $\mathrm{Ni}(\mathrm{II})$ and $\mathrm{Cu}(\mathrm{II})$ binding properties of native and modified sugar beet pulp. Carbohydr Polym 49:23-31

Reynel-Avila HE, Mendoza-Castillo DI, Hernandez-Montoya V, Bonilla-Petriciolet A (2011) Multicomponent removal of heavy metal from aqueous solution using low-cost sorbents. In: Antizar-Ladislao B, Sheikholeslami R (eds) Water production and Wastewater Treatment, 1st edn. Editorial Nova Science Publishers, pp 69-99

Reynel-Avila HE, Bonilla-Petriciolet A, de la Rosa G (2012) Competitive sorption of $\mathrm{Pb}, \mathrm{Cd}$ and $\mathrm{Ni}$ on chicken feathers from binary aqueous solutions. Int J Chem React Eng. doi:10. $1515 / 1542-6580.2724$

Sajab MS, Chia CH, Zakaria S, Jani SM, Ayob MK, Chee KL, Khiew PS, Chiu WS (2011) Citric acid modified kenar core fibres for removal of methylene blue from aqueous solution. Bioresource Technol 102:7237-7243

Saka C, Sahin O, Kucuk MM (2012) Applications on agricultural and forest waste adsorbents for the removal of lead (II) from contaminated waters. Int J Environ Sci Technol 9:379-394

Sena Neto AR, Araujo MAM, Souza FVD, Mattoso LHC, Marconcini JM (2013) Characterization and comparative evaluation of thermal, structural, chemical, mechanical and morphological properties of six pineapple leaf fiber varieties for use in composites. Ind Crop Prod 43:529-537

Sidiras D, Politi D, Batzias F, Boukos N (2013) Efficient removal of hexavalent chromium from aqueous solutions using autohydrolyzed scots pine (pinus sylvestris) sawdust as adsorbent. Int $\mathbf{J}$ Environ Sci Technol 10:1337-1348

Srivastava VC, Mall ID, Mishra IM (2007) Multicomponent adsorption study of metal ions onto bagasse fly ash using Taguchi's design of experimental methodology. Ind Eng Chem Res 46:5697-5706

Srivastava VC, Mall ID, Mishra IM (2008) Antagonistic competitive equilibrium modeling for the adsorption of ternary metal ion mixtures from aqueous solution onto bagasse fly ash. Ind Eng Chem Res 47:3129-3137

Srivastava VC, Mall ID, Mishra IM (2009) Equilibrium modeling of ternary adsorption of metal ions onto rice husk ash. Ind Eng Chem Res 54:705-711

Sud D, Mahajan G, Kaur MP (2008) Agricultural waste material as potential adsorbent for sequestering heavy metal ions from aqueous solutions-a review. Bioresour Technol 99:6017-6027

Tan G, Yuan H, Liu Y, Xiao D (2010) Removal of lead from aqueous solution with native and chemically modified corncobs. J Hazard Mater 174:740-745

Vaughan T, Seo CW, Marshall WE (2001) Removal of selected metal ions from aqueous solution using modified corncobs. Bioresource Technol 78:133-139 
Volesky B (2001) Detoxification of metal-bearing effluents: biosorption for the next century. Hydrometallurgy 59:203-216

Wing RE (1996) Corn fiber citrate: preparation and ion-exchange properties. Ind Crop Prod 5:301-305
Zhu B, Fan T, Zhang D (2008) Adsorption of copper ions from aqueous solution by citric acid modified soybean straw. J Hazard Mater 153:300-308 